\title{
TRATAMENTOS BIOLÓGICO E QUÍMICO EM SEMENTES DE Cedrela fissilis PARA CONTROLE DE Rhizoctonia sp.
}

\author{
Marília Lazarotto $^{1}$, Marlove Fátima Brião Muniz² ${ }^{2}$ Rafael Beltrame ${ }^{3}$, \\ Álvaro Figueredo dos Santos ${ }^{4}$, Jucéli Müller ${ }^{5}$, Maristela Machado Araújo ${ }^{6}$
}

(recebido: 18 de outubro de 2010; aceito: 29 de novembro de 2012)

\begin{abstract}
RESUMO: Neste trabalho, objetivou-se avaliar o efeito de um fungicida protetor e de um produto biológico, utilizados isoladamente e combinados, no controle de patógenos presentes em sementes de cedro (Cedrela fissilis), especialmente de Rhizoctonia sp. Anteriormente ao tratamento das sementes, parte das sementes foi previamente inoculada com Rhizoctonia sp., isolado de sementes de cedro, e parte recebeu os tratamentos sem a inoculação. Após, as sementes foram submetidas a tratamentos com produto biológico em pó à base de Trichoderma spp. (aplicado isoladamente), fungicida Captan em pó (também aplicado isoladamente), combinação dos dois produtos aplicados em uma dose considerada máxima (100\%) e combinação de metade da dose de ambos os produtos (50\%) e ainda a testemunha. As avaliações constaram dos testes de germinação, sanidade em papel-filtro, emergência e das avaliações de mudas. Nenhum tratamento conseguiu erradicar Rhizoctonia sp. das sementes inoculadas, porém o tratamento com 100\% da dose de ambos os produtos reduziu sua incidência. A combinação de produto químico e biológico, apresenta-se como uma alternativa viável para o tratamento de sementes de cedro, especialmente no controle de Rhizoctonia sp.
\end{abstract}

Palavras-chave: Microbiolização de sementes, sementes florestais, Trichoderma spp., patógeno.

\section{BIOLOGICAL AND CHEMICAL TREATMENT OF Cedrela fissilis SEEDS FOR CONTROLLING Rhizoctonia sp.}

\begin{abstract}
This research evaluated the effect of a fungicide and a biological product, singly and combined, for the control of pathogens, especially Rhizoctonia sp., in seeds of Cedrela fissilis. Before the seeds treatment, the inoculation of Rhizoctonia sp., isolated from C. fissilis seeds in blotter-test and considered pathogenic for the specie, was done on half of the seeds used. After, the seeds were subjected to treatments with powder organic product based on Trichoderma spp. (singly), powder fungicide Captan (also singly), combination of two products in a maximum dose considered (100\%) and combination of half dose of both products, besides the control. After the seeds treatments the following tests were done: germination, emergence in vermiculite, with evaluations of seedlings and sanitary by blotter-test. No treatment could eradicate Rhizoctonia sp. inoculated seed, but the treatment with $100 \%$ of the dose of both products reduced its incidence. The combination of chemical and biological products can be a viable alternative for the treatment of C. fissililis seeds, especially in the control of Rhizoctonia sp.
\end{abstract}

Key words: Seeds microbiolization, forest seeds, Trichoderma spp., pathogen.

\section{INTRODUÇÃO}

A alta qualidade e o alto valor comercial da madeira de cedro (Cedrela fissilis Vellozo) a torna alvo do extrativismo e da exploração indiscriminada, mesmo nos dias atuais, acarretando em derrubadas desproporcionais nas formações vegetais onde ocorre naturalmente (RUIZ
FILHO et al., 2004). Espécie considerada madeira de lei, de grande valor econômico, entretanto, em crescente risco de extinção, o que causa, além de preocupações, a necessidade de se estabelecerem plantios e explorações racionais.

A contaminação das sementes e frutos de essências florestais pode ocorrer no momento da coleta, pois, muitas vezes, esta é feita diretamente no solo, ambiente de

\footnotetext{
${ }^{1}$ Engenheira Florestal, Doutoranda em Engenharia Florestal - Universidade Federal de Santa Maria/UFSM - Departamento de Defesa Fitossanitária/DFS - 97105-900 - Santa Maria, RS, Brasil - lilalazarotto@yahoo.com.br

${ }^{2}$ Engenheira Agrônoma, Professora Doutora em Fitotecnia - Universidade Federal de Santa Maria/UFSM - Departamento de Defesa Fitossanitária/DFS - 97105-900 - Santa Maria, RS, Brasil - marlovemuniz@yahoo.com.br

${ }^{3}$ Engenheiro Florestal, Professor Doutor em Engenharia Florestal - Universidade Federal de Pelotas/UFPel - Centro de Engenharias Rua Conde de Porto Alegre, 793 - 96010-290 - Pelotas, RS, Brasil - beltrame.rafael@yahoo.com.br

${ }^{4}$ Engenheiro Agrônomo, Pesquisador Doutor em Fitopatologia - Embrapa Florestas - Cx. P. 319 - $83411-000$ - Colombo, PR, Brasil alvaro@cnpf.embrapa.br

${ }^{5}$ Engenheira Agrônoma, Mestranda em Agronomia - Universidade Federal de Santa Maria/UFSM - Departamento de Defesa Fitossanitária/ DFS - 97105-900 - Santa Maria, RS, Brasil - juceli.muller@yahoo.com.br

${ }^{6}$ Engenheira Florestal, Professora Doutora em Engenharia Florestal - Universidade Federal de Santa Maria/UFSM - Departamento de Ciências Florestais - 97105-900 - Santa Maria, RS, Brasil - araujo.maristela@gmail.com
} 
sobrevivência de diversos fungos, incluindo saprófitas e parasitas facultativos, como Rhizoctonia spp. Resende et al. (2008) destacam que alguns fungos, dentre eles Rhizoctonia spp., são os grandes responsáveis pelo tombamento de mudas, ou "damping-off", em viveiros florestais. Vechiato (2010) ressaltou a ausência de informações oriundas de pesquisa sobre a patogenicidade dos fungos associados às sementes de florestais, métodos eficientes de detecção, taxa de transmissão e danos ocasionados à cultura subsequente, bem como a eficiência de produtos químicos e alternativos para o seu tratamento. Porém, apesar da importância de pesquisas relacionadas aos temas citados, estas ainda são incipientes.

O tratamento de sementes com micro-organismos antagônicos, também chamado de microbiolização de sementes, pode proporcionar controle de patógenos habitantes da superfície das sementes e de patógenos veiculados pelo solo (BETTIOL; GHINI, 1995). Segundo os mesmos autores, existem alguns fungos já conhecidos utilizados no tratamento de sementes como agentes de controle biológico: Aspergillus spp., Chaetomium spp., Gliocladium spp. e Trichoderma spp. Dentre os citados, fungos do gênero Trichoderma estão entre os mais utilizados, os quais são considerados saprófitas potentes e eficientes por atuarem como antagonistas de alguns fitopatógenos de importância econômica, e também por promoverem o crescimento de plantas (RESENDE et al., 2004). A preocupação com os riscos ao meio ambiente e a saúde humana, tem incentivado a pesquisa de métodos alternativos de controle de fitopatógenos. Moreira et al. (2002) ressaltam ainda o interesse crescente dos produtores em minimizar a utilização de controle químico. Nesse contexto, o controle de patógenos em sementes com a combinação de produtos químico e biológico, à base de antagonistas, pode ser uma alternativa viável para a redução do uso exclusivo de produtos sintéticos, proporcionando benefícios econômicos e ambientais.

Diante do exposto, neste trabalho, objetivou-se avaliar o efeito de um fungicida protetor e um produto biológico, utilizados isoladamente e combinados, no controle de patógenos presentes em sementes de cedro, especialmente de Rhizoctonia sp., bem como seus efeitos sobre o vigor de mudas da espécie.

\section{MATERIAL E MÉTODOS}

\subsection{Origem das sementes e local dos experimentos}

As sementes de cedro foram obtidas por meio do Banco de Sementes da Embrapa Florestas localizado em
Colombo-PR. A amostra de sementes utilizada, procedente do município de Cerro Azul - PR e coletada em 2008, apresentou alta qualidade fisiológica, com germinação de $84 \%$ e emergência em vermiculita de $81 \%$ aos 35 dias (LAZAROTTO, 2010). Dessa forma, buscou-se evitar que aspectos de baixa qualidade fisiológica das sementes pudessem interferir nos tratamentos, dificultando a interpretação dos resultados.

Todos os experimentos realizados com avaliação de mudas foram conduzidos em casa de vegetação, com irrigação diária, sem controle de temperatura e umidade, pertencente ao Laboratório de Silvicultura Juarez Martins Hoppe - Centro de Ciências Rurais - UFSM.

\subsection{Inoculação de Rhizoctonia sp.}

O isolado de Rhizoctonia sp. utilizado foi obtido das sementes de cedro o qual foi escolhido, pois apresentou-se como patogênico para plântulas da espécie (LAZAROTTO, 2010). Este foi mantido em placa de Petri com meio batata-dextrose-ágar (BDA) e sulfato de estreptomicina, por dez dias até seu uso. Para que houvesse garantia de pureza dos fungos isolados, foi feita a repicagem com apenas uma unidade formadora de colônia (UFC) que, no caso de Rhizoctonia sp., foi um pequeno fragmento de hifa retirado de placas de meio ágar-água (AA) e transferido para meio batata-dextroseágar (BDA). A inoculação ocorreu por contato das sementes na cultura fúngica por 24 horas. Antes do contato, as sementes foram previamente desinfestadas com álcool 70\% (30 segundos) e hipoclorito de sódio 1\% ( 2 minutos), lavadas em água destilada esterilizada e deixadas secar sob papel filtro esterilizado (BENETTI et al., 2009). As sementes que não foram inoculadas com Rhizoctonia sp. ficaram em contato, por 24 horas, apenas em meio BDA. Após os procedimentos descritos anteriormente, as sementes foram colocadas em placas de vidro, fechadas, em ambiente de laboratório por 72 horas para posterior aplicação do produto biológico e do químico.

\subsection{Tratamento das sementes}

Após a inoculação das sementes, descrita no item anterior, as sementes foram submetidas a tratamentos com o produto biológico à base de Trichoderma spp. e fungicida protetor Captan 500 PM, na forma de pómolhável. Inicialmente, aplicaram-se os tratamentos nas sementes sem inoculação de Rhizoctonia sp.: $\mathrm{T}_{0}$ testemunha; $\mathrm{T}_{1}$ - Agrotrich Plus ${ }^{\circledR}$ com 0,25 g/ $100 \mathrm{~g}$ de

Cerne, Lavras, v. 19, n. 1, p. 169-175, jan./mar. 2013 
sementes (100\% dose); $\mathrm{T}_{2}$ - Captan com 0,18 g/ $100 \mathrm{~g}$ de sementes $(100 \%$ dose $) ; \mathrm{T}_{3}-$ Agrotrich Plus ${ }^{\circledR}+$ Captan com $0,25+0,18 \mathrm{~g} / 100 \mathrm{~g}$ de sementes (100\% dose) e $\mathrm{T}_{4}$ - Agrotrich Plus ${ }^{\circledR}+$ Captan 0,125 + 0,09 g/ 100 g de sementes $(50 \%$ dose). Além destes, ainda foram realizados tratamentos com os mesmos produtos, nas mesmas doses, porém com inoculação de Rhizoctonia sp., constituindo os tratamentos $\mathrm{T}_{5} \mathrm{~T}_{6}, \mathrm{~T}_{7}, \mathrm{~T}_{8}$ e $\mathrm{T}_{9}$. Para a aplicação dos produtos biológico e químico, os produtos e as sementes foram colocados em frascos de vidro de $500 \mathrm{ml}$, aos quais adicionou-se água destilada esterilizada (5\% do peso total das sementes). Os frascos foram agitados, manualmente, por cinco minutos. Para os tratamentos testemunha - sem e com inoculação ( $T_{0}$ e $\mathrm{T}_{5}$ ), o mesmo procedimento foi adotado, porém apenas com água destilada esterilizada (5\% do peso total das sementes).

\subsection{Avaliações}

Após a realização dos tratamentos das sementes, estas foram submetidas a avaliações de: a) germinação: com 200 sementes, divididas em quatro repetições de 50 , em rolo de papel, recomendado por Wielewicki et al. (2006) para sementes de cedro, umedecido com água destilada esterilizada (2,5 vezes o peso do papel seco). A desinfestação das sementes foi realizada como descrito no item 2.2. A incubação foi realizada em câmara com temperatura controlada de $25^{\circ} \mathrm{C}$ e fotoperíodo de 12 horas com luz branca constante. A avaliação de germinação realizou-se aos 14 dias, computando-se plântulas normais, anormais, sementes duras e mortas, conforme descrições de Brasil (2009); b) teste de sanidade em papel-filtro: com 200 sementes, divididas em quatro repetições de 50, distribuídas em caixas de plástico transparente, previamente desinfestadas com solução de hipoclorito de sódio $1 \%$, forradas com duas folhas de papel filtro esterilizadas e umedecidas com água destilada esterilizada. A incubação foi realizada em câmara com temperatura controlada a $22^{\circ} \mathrm{C} \pm 3^{\circ} \mathrm{C}$, e fotoperíodo de 12 horas com luz branca e 12 horas sem luz, durante sete dias, quando ocorreu a avaliação e identificação dos fungos através de descrições de morfologia na literatura especializada. Os dados da incidência dos fungos foram expressos em percentagem. c) emergência em viveiro: com 100 sementes, divididas em quatro repetições de 25 , semeadas em bandejas de isopor de 128 células $\left(25,09 \mathrm{~cm}^{3} /\right.$ célula), previamente desinfestadas com imersão em hipoclorito de sódio $1 \%$ por 24 horas, preenchidas com vermiculita fina. As avaliações realizaram-se aos 35 dias, computandose o número de mudas emergidas, sendo os resultados expressos em percentagem. Após a contagem de emergência, realizaram-se as avaliações seguintes: d) comprimento da muda: mediram-se 10 mudas por repetição, com auxílio de régua graduada; após, fez-se a média e os resultados foram expressos em $\mathrm{cm} /$ muda; e) massa fresca de mudas: todas as mudas de cada repetição foram pesadas em balança analítica de precisão $0,01 \mathrm{~g}$. Foi realizada a média por repetição e os resultados foram expressos em g/muda; f) massa seca de mudas: as mudas utilizadas na determinação da massa fresca foram acondicionadas em sacos de papel e colocadas em estufa sob temperatura de $80^{\circ} \mathrm{C} \pm 3^{\circ} \mathrm{C}$, por 24 horas, para posterior pesagem (CHEROBINI et al., 2008). Os resultados foram expressos em g/muda.

\subsection{Procedimento estatístico}

O delineamento experimental utilizado foi inteiramente casualizado, com quatro repetições para cada teste realizado. A comparação das médias foi realizada por meio do teste de Tukey, a 5\% de probabilidade, com arranjo bifatorial 2 x 5 (inoculação ou ausência de inoculação x tratamentos). Para a análise de variância, os dados obtidos em percentagem foram transformados segundo arc sen $\sqrt{x / 100}$.

\section{RESULTADOS E DISCUSSÃO}

As interações entre presença ou ausência (de inóculo de Rhizoctonia sp.) e tratamentos foram significativas para todas as variáveis observadas no teste de germinação (Tabela 1), exceto para sementes mortas que não estão representadas. Para a variável plântulas normais, não houve diferença entre as sementes inoculadas e não-inoculadas, exceto para o tratamento com $100 \%$ da dose do produto biológico e químico, com maior percentagem de plântulas normais, quando as sementes não foram inoculadas com o patógeno. Somente no tratamento químico houve diferença na porcentagem de plântulas anormais. Não foram encontradas sementes duras no final do teste de germinação para testemunha, tratamento químico e para a combinação $50 \% \mathrm{~A}+\mathrm{C}$.

Analisando somente os resultados do teste de germinação, não foi possível estabelecer o melhor tratamento (Tabela 1). Além disso, a inoculação de

Cerne, Lavras, v. 19, n. 1, p. 169-175, jan./mar. 2013 
Rhizoctonia sp., de uma forma geral, não afetou a germinação de sementes; com exceção para o tratamento químico, verificando-se menor porcentagem de plântulas anormais para sementes inoculadas; e para tratamento $100 \% \mathrm{~A}+\mathrm{C}$ que proporcionou menor porcentagem de plântulas normais para sementes inoculadas.

Observa-se interação significativa entre a inoculação de sementes e os tratamentos testados nos testes de sanidade (Tabela 2).

Tabela 1 - Resultados médios (\%) do teste de germinação de sementes de cedro inoculadas (I) e não-inoculadas (NI) com Rhizoctonia sp. após diferentes tratamentos das sementes.

Table 1 - Means (\%) of the germination test of C. fissilis seeds inoculated (I) and non-inoculated (NI) with Rhizoctonia sp. after different treatments of the seeds.

\begin{tabular}{lcccccc}
\hline \multirow{2}{*}{ Variável } & \multirow{2}{*}{ Inóculo } & \multicolumn{5}{c}{ Tratamentos } \\
\cline { 3 - 7 } & & Teste & Biológico (A) & Químico (C) & $100 \% \mathrm{~A}+\mathrm{C}$ & $50 \% \mathrm{~A}+\mathrm{C}$ \\
\hline Plântulas Normais & $\mathrm{I}$ & $79 \mathrm{Aa}^{*}$ & $80 \mathrm{Aa}$ & $80 \mathrm{Aa}$ & $69 \mathrm{Ba}$ & $77 \mathrm{Aa}$ \\
CV $(\%): 9,8$ & $\mathrm{NI}$ & $82 \mathrm{Aa}$ & $82 \mathrm{Aa}$ & $82 \mathrm{Aa}$ & $93 \mathrm{Aa}$ & $88 \mathrm{Aa}$ \\
\hline Plântulas Anormais & $\mathrm{I}$ & $6 \mathrm{Aa}$ & $4 \mathrm{Aa}$ & $2 \mathrm{Ba}$ & $9 \mathrm{Aa}$ & $5 \mathrm{Aa}$ \\
CV $(\%): 40,5$ & $\mathrm{NI}$ & $9 \mathrm{Aab}$ & $7 \mathrm{Aab}$ & $16 \mathrm{Aa}$ & $3 \mathrm{Ab}$ & $10 \mathrm{Aab}$ \\
\hline Sementes Duras & $\mathrm{I}$ & $2 \mathrm{Ab}$ & $2 \mathrm{Bb}$ & $10 \mathrm{Aa}$ & $9 \mathrm{Aa}$ & $11 \mathrm{Aa}$ \\
CV $(\%): 45,6$ & $\mathrm{NI}$ & $0 \mathrm{Ab}$ & $7 \mathrm{Aa}$ & $0 \mathrm{Bb}$ & $2 \mathrm{Bab}$ & $0 \mathrm{Bb}$ \\
\hline
\end{tabular}

* Médias seguidas por mesma letra maiúscula na coluna e minúscula na linha não diferem entre si pelo teste de Tukey ao nível de 5\% de probabilidade. Em que: Teste: Testemunha; Biológico (A): Agrotrich Plus ${ }^{\circledR}$ (0,25 g/100 g de sementes); Químico (C): Captan (0,18 g/ $100 \mathrm{~g}$ sementes); 100\% A+C: 100\% da dose de Agrotrich Plus ${ }^{\circledR}+$ Captan; 50\% A+C: 50\% da dose de Agrotrich Plus ${ }^{\circledR}+$ Captan.

Tabela 2 - Incidência de fungos (\%) associados à sementes de cedro inoculadas (I) e não-inoculadas (NI) com Rhizoctonia sp. após diferentes tratamentos das sementes.

Table 2 - Fungal incidence (\%) associated with C. fissilis seeds inoculated (I) and non-inoculated (NI) with Rhizoctonia sp. after different treatments of the seeds.

\begin{tabular}{lcccccc}
\hline \multirow{2}{*}{ Variável } & Inóculo & \multicolumn{5}{c}{ Tratamentos } \\
\cline { 3 - 7 } & & Teste & Biológico (A) & Químico (C) & $100 \% \mathrm{~A}+\mathrm{C}$ & $50 \% \mathrm{~A}+\mathrm{C}$ \\
\hline Colletotrichum sp. & $\mathrm{I}$ & $30 \mathrm{Aa} *$ & $7 \mathrm{Acd}$ & $19 \mathrm{Aab}$ & $0 \mathrm{Ad}$ & $16 \mathrm{Abc}$ \\
CV (\%): 33,7 & $\mathrm{NI}$ & $0 \mathrm{Bb}$ & $0 \mathrm{Bb}$ & $0 \mathrm{Bb}$ & $0 \mathrm{Ab}$ & $10 \mathrm{Aa}$ \\
\hline Fusarium sp. & $\mathrm{I}$ & $8 \mathrm{Ab}$ & $10 \mathrm{Aab}$ & $0 \mathrm{Ac}$ & $0 \mathrm{Bc}$ & $19 \mathrm{Ba}$ \\
CV (\%): 27,7 & $\mathrm{NI}$ & $0 \mathrm{Bb}$ & $0 \mathrm{Bb}$ & $0 \mathrm{Ab}$ & $35 \mathrm{Aa}$ & $31 \mathrm{Aa}$ \\
\hline Penicillium sp. & $\mathrm{I}$ & $19 \mathrm{Ab}$ & $31 \mathrm{Aa}$ & $0 \mathrm{Bc}$ & $0 \mathrm{Ac}$ & $0 \mathrm{Ac}$ \\
CV (\%): 20,7 & $\mathrm{NI}$ & $11 \mathrm{Aa}$ & $12 \mathrm{Ba}$ & $8 \mathrm{Aa}$ & $0 \mathrm{Ab}$ & $1 \mathrm{Ab}$ \\
\hline Phomopsis sp. & $\mathrm{I}$ & $15 \mathrm{Ba}$ & $21 \mathrm{Ba}$ & $16 \mathrm{Ba}$ & $24 \mathrm{Aa}$ & $17 \mathrm{Ba}$ \\
CV (\%): 13,3 & $\mathrm{NI}$ & $31 \mathrm{Ab}$ & $52 \mathrm{Aa}$ & $28 \mathrm{Aa}$ & $0 \mathrm{Bc}$ & $33 \mathrm{Ab}$ \\
\hline Rhizoctonia sp. & $\mathrm{I}$ & $42 \mathrm{Aa}$ & $34 \mathrm{Aab}$ & $39 \mathrm{Aab}$ & $18 \mathrm{Ab}$ & $37 \mathrm{Aab}$ \\
CV $(\%): 15,5$ & $\mathrm{NI}$ & $15 \mathrm{Ba}$ & $0 \mathrm{Bb}$ & $9 \mathrm{Ba}$ & $0 \mathrm{Bb}$ & $0 \mathrm{Bb}$ \\
\hline Sementes Sadias & $\mathrm{I}$ & $0 \mathrm{Ac}$ & $0 \mathrm{Bc}$ & $26 \mathrm{Bab}$ & $48 \mathrm{Ba}$ & $17 \mathrm{Ab}$ \\
CV $(\%): 21,1$ & $\mathrm{NI}$ & $0 \mathrm{Ac}$ & $13 \mathrm{Ab}$ & $31 \mathrm{Ab}$ & $65 \mathrm{Aa}$ & $20 \mathrm{Ab}$ \\
\hline
\end{tabular}

* Médias seguidas por mesma letra maiúscula na coluna e minúscula na linha não diferem entre si pelo teste de Tukey ao nível de 5\% de probabilidade. Em que: Teste: Testemunha; Biológico (A): Agrotrich Plus ${ }^{\circledR}$ (250 g/100 kg de sementes); Químico (C): Captan $(180 \mathrm{~g} / 100 \mathrm{~kg}$ sementes $) ; 100 \%$ A+C: $100 \%$ da dose de Agrotrich Plus ${ }^{\circledR}+$ Captan; $50 \%$ A+C: $50 \%$ da dose de Agrotrich Plus ${ }^{\circledR}+$ Captan.

\section{Cerne, Lavras, v. 19, n. 1, p. 169-175, jan./mar. 2013}


Colletotrichum sp. apareceu quase que, exclusivamente, nas sementes inoculadas com Rhizoctonia sp., com maior incidência na testemunha, tendo $100 \%$ de controle com o tratamento com dose máxima de produtos combinados. Fusarium sp. obteve maiores percentagens de ocorrência no tratamento com combinação de produto biológico e químico $(50 \% \mathrm{~A}+\mathrm{C})$, e no tratamento com uso de apenas controle biológico o que pode ter ocorrido, pela eliminação de organismos antagonistas pelo tratamento. Penicillium sp. foi eliminado pelos tratamentos químico, combinação entre biológico e químico nas duas combinações testadas nas sementes inoculadas; para as não-inoculadas, esse fungo foi reduzido com a combinação dos produtos nas duas doses testadas. As maiores incidências de Phomopsis sp. foram encontradas nas sementes não-inoculadas com Rhizoctonia sp., exceto no tratamento $100 \% \mathrm{~A}+\mathrm{C}$. Rhizoctonia sp., como era de se esperar, foi mais frequente nas sementes inoculadas e nenhum tratamento conseguiu erradicá-lo, porém o tratamento com $100 \%$ da dose de ambos os produtos testados foi o mais eficiente, proporcionando redução de $42 \%$ para $18 \%$ de sua incidência.

Para as sementes não-inoculadas, o tratamento biológico e os dois combinados (biológico + químico) erradicaram o patógeno (Rhizoctonia sp.) que estava infectando naturalmente as sementes. Lucon et al. (2009) encontraram isolados de Trichoderma spp. capazes de reduzir o tombamento causado por Rhizoctonia solani em mudas de pepino, comprovando a ação do antagonista sobre patógenos desse gênero. Com relação às sementes sadias, a combinação entre os produtos na dose máxima testada, foi eficaz chegando a manter $65 \%$ e $48 \%$ das sementes sadias, para sementes não-inoculadas e inoculadas, respectivamente.

Alguns estudos têm demonstrado o êxito do uso combinado de produtos biológicos à base de fungos ou bactérias com produtos químicos, especialmente entre espécies agrícolas. Luz (2003a) testou o efeito da combinação dos controles biológico, à base de Paenibacillus macerans, com controle químico no tratamento de semente de trigo (Triticum aestivum) e constatou a redução de alguns patógenos nas sementes, tais como: Fusarium graminearum, Bipolaris sorokiniana, Drechslera tritici-repentis e Aspergillus spp., com a combinação dos tratamentos. Howell et al. (1997) encontrou resultados positivos da combinação de fungicidas e produto biológico à base de Trichoderma virens no tratamento de sementes de algodão (Gossypium hirsutum).
Luz (2003b) testou o efeito da combinação dos controles biológico, à base de Paenibacillus macerans, com controle químico no tratamento de semente de milho (Zea mays) os quais eliminaram por completo todos os patógenos da semente de milho; o autor ainda destacou que este tipo de combinação auxilia na redução do uso de fungicidas, para alcançar a agricultura sustentável e proteger o ambiente. Para espécies florestais, tem-se o exemplo de trabalho realizado por Silva et al. (2003) com tratamento de sementes de paineira - Chorisia speciosa (Ceiba speciosa), combinando produto biológico à base de Bacillus subtilis com diferentes fungicidas em doses variadas, que resultou em menor percentual de micro-organismos nas sementes tratadas com a mistura de dois fungicidas mais o produto biológico.

As interações entre presença ou ausência de inóculo e os tratamentos utilizados foram significativos (Tabela 3). Na emergência (E35), as diferenças entre tratamentos em sementes inoculadas e não-inoculadas ocorreram apenas nos tratamentos químicos e em $100 \%$ $\mathrm{A}+\mathrm{C}$, onde as sementes não-inoculadas apresentaram maior valor em percentagem para essa variável. A menor eficiência desses tratamentos sobre a emergência de plântulas oriundas de sementes inoculadas, pode ter ocorrido, pela alta densidade do inóculo, levando ao tombamento de plântulas pré ou pós- emergente. Com relação à emergência, para as sementes inoculadas, o tratamento $50 \% \mathrm{~A}+\mathrm{C}$ foi o mais eficiente, conseguindo elevar a emergência em 17\% com relação à testemunha, em razão da sua capacidade de redução do inóculo.

Luz (2003a) verificou efeitos benéficos na germinação e no rendimento de grãos de trigo, com a integração de controle biológico (à base de Paenibacillus macerans), com controle químico, mesmo quando a dose desses produtos foi reduzida pela metade. O mesmo foi verificado por Luz (2003b), porém com grãos de milho e produtos químicos diferentes.

As sementes inoculadas tiveram maior comprimento de mudas em comparação às não-inoculadas na testemunha, no tratamento químico e no tratamento $100 \%$ $\mathrm{A}+\mathrm{C}$; nos outros tratamentos, todas foram estatisticamente iguais (Tabela 3). Para essa variável, sementes não inoculadas submetidas aos tratamentos com produto biológico e com a combinação de $50 \%$ da dose combinada, apresentaram melhores resultados. Mudas originadas de sementes inoculadas apresentaram maior peso de massa fresca para todos os tratamentos; exceto para testemunha e para o tratamento $50 \%$ de $\mathrm{A}+\mathrm{C}$ que foram similares

Cerne, Lavras, v. 19, n. 1, p. 169-175, jan./mar. 2013 
Tabela 3 - Avaliação da qualidade de mudas de cedro originadas de sementes inoculadas (I) e não-inoculadas (NI) com Rhizoctonia sp. após diferentes tratamentos.

Table 3 - Assessment of the quality of C. fissilis seedlings originating from seeds inoculated (I) and non-inoculated (NI) with Rhizoctonia sp. after different treatments.

\begin{tabular}{lcccccc}
\hline \multirow{2}{*}{ Variável } & Inóculo & \multicolumn{5}{c}{ Tratamentos } \\
\cline { 3 - 7 } & & Teste & Biológico (A) & Químico (C) & $100 \% \mathrm{~A}+\mathrm{C}$ & $50 \% \mathrm{~A}+\mathrm{C}$ \\
\hline E35 (\%) & $\mathrm{I}$ & $69 \mathrm{Ab}^{*}$ & $73 \mathrm{Aab}$ & $70 \mathrm{Bab}$ & $75 \mathrm{Bab}$ & $86 \mathrm{Aa}$ \\
$\mathrm{CV}(\%): 8,7$ & $\mathrm{NI}$ & $77 \mathrm{Abc}$ & $69 \mathrm{Ac}$ & $91 \mathrm{Aa}$ & $89 \mathrm{Aab}$ & $90 \mathrm{Aab}$ \\
\hline CM(cm/muda) & $\mathrm{I}$ & $8,89 \mathrm{Aa}$ & $9,66 \mathrm{Aa}$ & $8,94 \mathrm{Aa}$ & $9,15 \mathrm{Aa}$ & $9,30 \mathrm{Aa}$ \\
CV (\%): 8,2 & $\mathrm{NI}$ & $8,03 \mathrm{Bb}$ & $9,30 \mathrm{Aa}$ & $7,93 \mathrm{Bb}$ & $8,45 \mathrm{Bb}$ & $9,60 \mathrm{Aa}$ \\
\hline MF (g/muda) & $\mathrm{I}$ & $0,241 \mathrm{Aa}$ & $0,241 \mathrm{Aa}$ & $0,257 \mathrm{Aa}$ & $0,254 \mathrm{Aa}$ & $0,241 \mathrm{Aa}$ \\
CV (\%): 3,8 & $\mathrm{NI}$ & $0,266 \mathrm{Aa}$ & $0,212 \mathrm{Bbc}$ & $0,218 \mathrm{Bb}$ & $0,172 \mathrm{Bc}$ & $0,231 \mathrm{Aab}$ \\
\hline MS (g/muda) & $\mathrm{I}$ & $0,031 \mathrm{Bc}$ & $0,039 \mathrm{Aab}$ & $0,035 \mathrm{Abc}$ & $0,035 \mathrm{Abc}$ & $0,041 \mathrm{Aa}$ \\
$\mathrm{CV}(\%): 8,4$ & $\mathrm{NI}$ & $0,040 \mathrm{Aa}$ & $0,033 \mathrm{Bb}$ & $0,030 \mathrm{Bb}$ & $0,021 \mathrm{Bc}$ & $0,034 \mathrm{Bb}$ \\
\hline
\end{tabular}

* Médias seguidas por mesma letra maiúscula, na coluna, e minúscula, na linha, não diferem entre si pelo teste de Tukey ao nível de 5\% de probabilidade. Em que: E35: Emergência aos 35 dias; CM: cComprimentod e Mudas; MF: Massa Fresca de Mudas; MS: Massa Seca de Mudas; Teste: Testemunha; Biológico (A): Agrotrich Plus ${ }^{\circledR}$ (250 g/100 kg de sementes); Químico (C): Captan (180 g/ $100 \mathrm{~kg}$ sementes) $100 \%$ A+C: $100 \%$ da dose de Agrotrich Plus ${ }^{\circledR}+$ Captan; $50 \%$ A+C: $50 \%$ da dose de Agrotrich Plus ${ }^{\circledR}+$ Captan.

estatisticamente. Somente as sementes não-inoculadas tiveram diferenças entre os tratamentos, onde a testemunha e o tratamento $50 \%$ de $\mathrm{A}+\mathrm{C}$ tiveram as médias mais elevadas para essa variável. Quanto a massa seca, mudas originas de sementes inoculadas apresentaram maior valor, exceto para testemunha onde os resultados se inverteram.

De maneira geral, os tratamentos que continham produto biológico à base de Trichoderma spp. obtiveram maiores médias nas variáveis relacionadas ao vigor de mudas, como no caso da emergência e testes de desempenho de plântulas. Segundo Lucon (2009), a promoção de crescimento realizada por Trichoderma spp. estava, inicialmente, associada ao controle de micro-organismos prejudiciais da rizosfera. Porém, mais recentemente, esta característica de promoção de crescimento foi relacionada à produção de hormônios ou a outros fatores de crescimento, já que algumas linhagens desse antagonista aumentam a superfície total do sistema radicular, possibilitando um maior acesso aos elementos minerais nele presentes.

Uma vantagem da interação de um fungicida com um antagonista, segundo Luz (2003a), parece ser o controle inicial de patógenos pelo fungicida e a habilidade do antagonista de desenvolver e persistir nas raízes, reduzindo a infecção dos patógenos; mais tarde, no desenvolvimento de plantas, também, essa prática integrada de controle pode atrasar o desenvolvimento de resistência dos patógenos ao fungicida.

\section{CONCLUSÕES}

Os tratamentos que contêm produto biológico à base de Trichoderma spp. influenciam positivamente no vigor de mudas de cedro, entretanto o uso somente do produto químico apresenta efeito semelhante ao produto biológico, utilizado isoladamente. $\mathrm{O}$ tratamento com combinação de produto biológico à base de Trichoderma spp. e produto químico apresenta-se como uma alternativa viável e promissora para o controle de Rhizoctonia sp., associado à sementes de cedro.

\section{AGRADECIMENTOS}

À Coordenação de Aperfeiçoamento de Pessoal de Nível Superior (CAPES), pela concessão da bolsa de mestrado e à Embrapa Florestas, pelo fornecimento das sementes de cedro.

\section{REFERÊNCIAS}

BENETTI, S. C.; SANTOS, A. F. dos; MEDEIROS, A. C. S.; JACCOUD FILHO, D. S. Levantamento de fungos em sementes de cedro e avaliação da patogenicidade de Fusarium sp. e Pestalotia sp. Pesquisa Florestal Brasileira, Colombo, v. 58, p. 79-83, 2009.

BETTIOL, W.; GHINI, R. Controle biológico. In: BERGAMIN FILHO, A.; KIMATI, H.; AMORIN, L. (Ed.). Manual de fitopatologia: princípios e conceitos. 3. ed. São Paulo: Agronômica Ceres, 1995. v. 2, p. 717-728. 
BRASIL. Ministério da Agricultura, Pecuária e Abastecimento. Regras para análise de sementes. Brasília: MAPA/ACS, 2009. 399 p.

CHEROBINI, E. A. I.; MUNIZ, M. F. B.; BLUME, E. Avaliação da qualidade de sementes e mudas de cedro. Ciência Florestal, Santa Maria, v. 18, n. 1, p. 65-73, jan./mar. 2008.

HOWELL, C. R.; DEVAY, J. E.; GARBER, R. H.; BATSON, W. E. Field control of seedling diseases with Trichoderma virens in combination with fungicide seed treatments. The Journal of Cotton Science, Baton Rouge, v. 1, p. 15-20, 1997.

LAZAROTTO, M. Qualidade fisiológica e sanitária de sementes de cedro e patogenicidade de Rhizoctonia spp. 2010. 90 p. Dissertação (Mestrado em Engenharia Florestal) Universidade Federal de Santa Maria, Santa Maria, 2010.

LUCON, C. M. M. Promoção de crescimento de plantas com o uso de Trichoderma spp. Disponível em: <http:// www.infobibos.com/Artigos/2009_1/trichoderma/index.htm> Acesso em: 9 dez. 2009.

LUCON, C. M. M.; KOIKE, C. M.; ISHIKAWA, A. I.; PATRÍCIO, F. R. A.; HARAKAVA, R. Bioprospecção de isolados de Trichoderma spp. para o controle de Rhizoctonia solani na produção de mudas de pepino. Pesquisa

Agropecuária Brasileira, Brasília, v. 44, n. 3, p. 225-232, mar. 2009.

LUZ, W. C. Avaliação dos tratamentos biológico e químico na redução de patógenos em semente de trigo. Fitopatologia Brasileira, Brasília, v. 28, n. 1, p. 93-95, jan./fev. 2003 a.

LUZ, W. C. Combinação dos tratamentos biológico e químico de semente de milho. Fitopatologia Brasileira, Brasília, v. 28, n. 1, p. 37-40, jan./fev. 2003 b.
MOREIRA, L. M.; MAY-DE MIO, L. L.; VALDEBENITOSANHUEZA, R. M.; LIMA, M. L. R. Z. C.; POSSAMAI, J. C. controle em pós-colheita de Monilinia fructicola em pêssegos. Fitopatologia Brasileira, Brasília, v. 27, n. 4, p. 395-398, 2002.

RESENDE, M. L.; OLIVEIRA, J. A.; GUIMARÃES, R. M.; PINHO, R. G. von; VIEIRA, A. R. Inoculação de sementes de milho utilizando o Trichoderma harzianum como promotor de crescimento. Ciência e Agrotecnologia, Lavras, v. 28, n. 4, p. 793-798, jul./ago. 2004.

RESENDE, M. L. V.; PÁDUA, M. A.; TOYOTA, M. Manejo das doenças associadas a viveiros florestais. In: DAVIDE, A. C.; SILVA, E. A. A. (Ed.). Produção de sementes e mudas de espécies florestais. Lavras: UFLA, 2008. p. 141-153.

RUIZ FILHO, R. R.; SANTOS, A. F.; MEDEIROS, A. C.; JACCOUD FILHO, D. S. Fungos associados às sementes de cedro. Summa Phytopathologica, Botucatu, v. 30, n. 4, p. 494-496, 2004.

SILVA, R. T. V.; HOMECHIN, M.; FONSECA, E. P.; SANTIAGO, D. C. Tratamento de sementes e armazenamento na sanidade de sementes de paineira (Chorisia speciosa St. Hil). Semina: Ciências Agrárias, Londrina, v. 24, n. 2, p. 255-260, jul./dez. 2003.

VECHIATO, M. H. Importância da qualidade sanitária de sementes de florestais na produção de mudas. Disponível em: <http://www.infobibos.com/Artigos/2010_3/

SementesFlorestais/index.htm>. Acesso em: 26 jul. 2010.

WIELEWICKI, A. P.; LEONHARDT, C.; SCHLINDWEIN, G.; MEDEIROS, A. C. S. Proposta de padrões de germinação e teor de água para sementes de algumas espécies florestais presentes na região sul do Brasil. Revista Brasileira de Sementes, Brasília, v. 28, n. 3, p. 191-197, 2006. 
